\title{
Effects of social network incentives and financial incentives on physical activity and social capital among older women: a randomized controlled trial
}

Ryo Yamashita ${ }^{*}$, Shinji Sato ${ }^{2}$, Ryoichi Akase ${ }^{3}$, Tatsuo Doi ${ }^{4}$, Shigeki Tsuzuku ${ }^{5}$, Toyohiko Yokoi ${ }^{6}$, Shingo Otsuki ${ }^{6}$ and Eisaku Harada ${ }^{1,3}$

\begin{abstract}
Background: Financial incentives have been used to increase physical activity. However, the benefit of financial incentives is lost when an intervention ends. Thus, for this study, we combined social network incentives that leverage the power of peer pressure with financial incentives. Few reports have examined the impact of physical activity on social capital. Therefore, the main goal of this study was to ascertain whether a combination of two incentives could lead to more significant changes in physical activity and social capital during and after an intervention.
\end{abstract}

Methods: The participants were 39 older women over 65 years of age in Kumamoto, Japan. The participants were randomly divided into a financial incentive group (FI group) and a social network incentive plus financial incentive group ( $\mathrm{SNI}+\mathrm{Fl}$ group). Both groups underwent a three-month intervention. Measurements of physical activity and social capital were performed before and after the intervention. Additionally, the effects of the incentives on physical activity and social capital maintenance were measured 6 months postintervention. The financial incentive group received a payment ranging from US\$4.40 to US\$6.20 per month, depending on the number of steps taken during the intervention. For the other group, we provided a social network incentive in addition to the financial incentive. The SNI + Fl group walked in groups of three people to use the power of peer pressure.

Results: A two-way ANOVA revealed that in terms of physical activity, there was a statistically significant interaction between group and time $(p=0.017)$. The FI group showed no statistically significant improvement in physical activity during the observation period. In terms of the value of social capital, there was no significant interaction between group and time.

* Correspondence: ry0513@hotmail.co.jp

'Kumamoto Institute of Total Fitness, 6-8-1 Yamamuro, Kita-ku, Kumamoto 860-8518, Japan

Full list of author information is available at the end of the article

(c) The Author(s). 2021 Open Access This article is licensed under a Creative Commons Attribution 4.0 International License, which permits use, sharing, adaptation, distribution and reproduction in any medium or format, as long as you give appropriate credit to the original author(s) and the source, provide a link to the Creative Commons licence, and indicate if changes were made. The images or other third party material in this article are included in the article's Creative Commons licence, unless indicated otherwise in a credit line to the material. If material is not included in the article's Creative Commons licence and your intended use is not permitted by statutory regulation or exceeds the permitted use, you will need to obtain permission directly from the copyright holder. To view a copy of this licence, visit http://creativecommons.org/licenses/by/4.0/ The Creative Commons Public Domain Dedication waiver (http://creativecommons.org/publicdomain/zero/1.0/) applies to the data made available in this article, unless otherwise stated in a credit line to the data. 
(Continued from previous page)

Conclusion: Our results suggest that social network incentives, in combination with financial incentives, are more effective for promoting physical activity than financial incentives alone among older women and that these effects can continue after an intervention. In the meantime, further studies should be conducted on the effect of physical activity on social capital.

Trial registration: UMIN000038080, registered on 09/22/2019 (Retrospectively registered).

Keywords: Older women, Social network incentive, Financial incentive, Physical activity, Social capital

\section{Background}

It is common knowledge that an increase in physical activity improves health. It reduces the risk of mortality and cardiovascular diseases [1-4], improves physical function [5], and improves quality of life [6, 7]. Additionally, the preventive effects of cognitive impairment $[8,9]$, depression $[10,11]$, and cancer $[12,13]$ have been reported recently. Despite these beneficial effects, the level of physical activity is still low among the population $[14,15]$.

Previous studies have shown that financial incentives have been used to achieve behavioral change in physical activity in an effort to solve this problem $[16,17]$. However, the benefit of the incentive is lost when the intervention ends [18, 19], meaning that the effect of financial incentives is short-term. Therefore, in this study, we focused on social network incentives that leverage the power of peer pressure to regulate behavior [20]. An advanced study by Aharony et al. [21] divided 108 active young people into three groups: i) a control group, ii) a peer-view group, and iii) a peer-reward group; participants were rewarded according to their increase in physical activity. In the control group, individuals were rewarded for their own increased physical activity [21]. In the peer-view group, the participant was shown his/her buddies' activity levels, but was still rewarded for his/her own activity level. In the peerreward group, the buddies received a reward proportional to the participant's activity level. As a result, the peer-reward group yielded a significantly larger increase in activity level than both the control and peer-view groups. In their study, creating peer pressure by adding two "buddies" to one person was necessary to achieve this benefit. Aharony et al. called this strategy "social network incentives." Furthermore, their study found that increased physical activity continues after the intervention has ended when financial incentives are combined with social network incentives. Therefore, combining social network incentives with financial incentives for increased physical activity may have a long-term effect. However, the participants in Aharony et al.'s study only included young people. In addition, their study did not explicitly present a randomized controlled trial. Thus, we hypothesized that the combination of social network incentives and financial incentives would have a longterm effect on physical activity in older persons, and decided to verify this using a randomized controlled trial.

Furthermore, Brach et al.'s [22] study demonstrated that physical activity plays a significant role in maintaining functional fitness in older women [22]. Additionally, a decrease in muscle strength and mass is likely to be a consequence of more physical inactivity. Therefore, it is important that older women increase their physical activity [23].

On the other hand, recent public health research revealed that individual health behavior was affected by social capital [24, 25]. This mechanism works in such a way that being integrated into a particular network means that people are under the influence of others in the same network, and as a result their individual health behavior is controlled [26]. Meanwhile, there have been no previous findings which showed that physical activity enhances individual-level social capital. Therefore, we assumed that encouraging walking in small groups using social network incentives should enhance individuallevel social capital.

The main goal of this study was to ascertain whether combining financial incentives with social network incentives could lead to more significant changes in physical activity and social capital among older women compared to financial incentives alone, during and after an intervention.

\section{Methods \\ Study design and participants}

This study was a randomized study in which participants were recruited by handing out leaflets in several different regions in Kumamoto, Japan. Forty-four older women over 65 years of age were recruited between August 2017 and September 2017.

After completing measurements before the intervention, participants drew a sealed envelope to determine whether they were allocated to the financial incentive group (FI group) or the FI plus social network incentive group (SNI + FI group).

During the intervention, two participants in the FI group and three in the SNI + FI group dropped out. Eventually, the study groups comprised 21 participants 
in the FI group and 18 participants in the SNI + FI group. The study flowchart is presented in Fig. 1.

Each participant in the FI group received a payment ranging from US $\$ 4.40$ to US\$6.20 per month, depending on the number of steps taken per day during the intervention as follows:

(a) A $\$ 4.40$ gift card if the average daily steps for a month was between 5000 and 7999 steps/day.

(b) A $\$ 6.20$ gift card if the average daily steps for a month were 8000 steps/day or more.

The SNI + FI group participants walked in groups of three people to utilize the power of peer pressure, in addition to receiving the financial incentive. Three people from the SNI + FI group selected the groups in the order in which they opened the envelopes, after grouping by randomization. Consequently, most groups did not know each other in advance. The groups of buddies remained the same over the three-month intervention in this study. The participants were informed that they would walk in groups of three people about once a week. Furthermore, their rewards were designed to reflect the largest number of steps taken among their "buddies." The buddy's overall step count results were communicated between themselves as they walked together. In addition, regarding the reflected rewards, the number of steps taken by all group members, the reflected number of steps taken, and their rewards were delivered to each group member once a month. The payment rewards ranged from US $\$ 4.40$ to US $\$ 6.20$ per month and were available for both groups. After the three-month intervention, the participants were not asked to walk with their peers. However, they could decide for themselves whether to walk or not. In the $\mathrm{SNI}+\mathrm{FI}$ group, if it became impossible even one in three people to walk together for whatever reason, the research was excluded.

Both groups underwent a three-month intervention between September 2017 and December 2017. Before the intervention, each group was assessed for age, body height, body weight, body mass index, and percentage of body fat. Measurements of physical activity and social capital were performed before and after each intervention. Additionally, the effects of the incentives on activity maintenance were measured 6 months after the intervention. The study design described above has followed the one in our previous study [27].

All participants provided written informed consent to participate in the study, which was approved by the ethics committee of Osaka Sangyo University (2017-JINRIN-016).

\section{Blinding}

Those assessing the outcomes were blinded to the grouping allocation; however, owing to the nature of the intervention, participants were not blind to their allocation. The FI group participants did not know about the SNI + FI group reward structure.

\section{Anthropometric measures}

Body height was measured to the nearest $0.1 \mathrm{~cm}$. Body weight was measured to the nearest $0.1 \mathrm{~kg}$ using a digital scale. Body mass index (BMI) was calculated using the formula $\mathrm{BMI}=$ body mass $(\mathrm{kg}) /(\text { body height }[\mathrm{m}])^{2}$. The percentage of body fat was calculated using the formula:

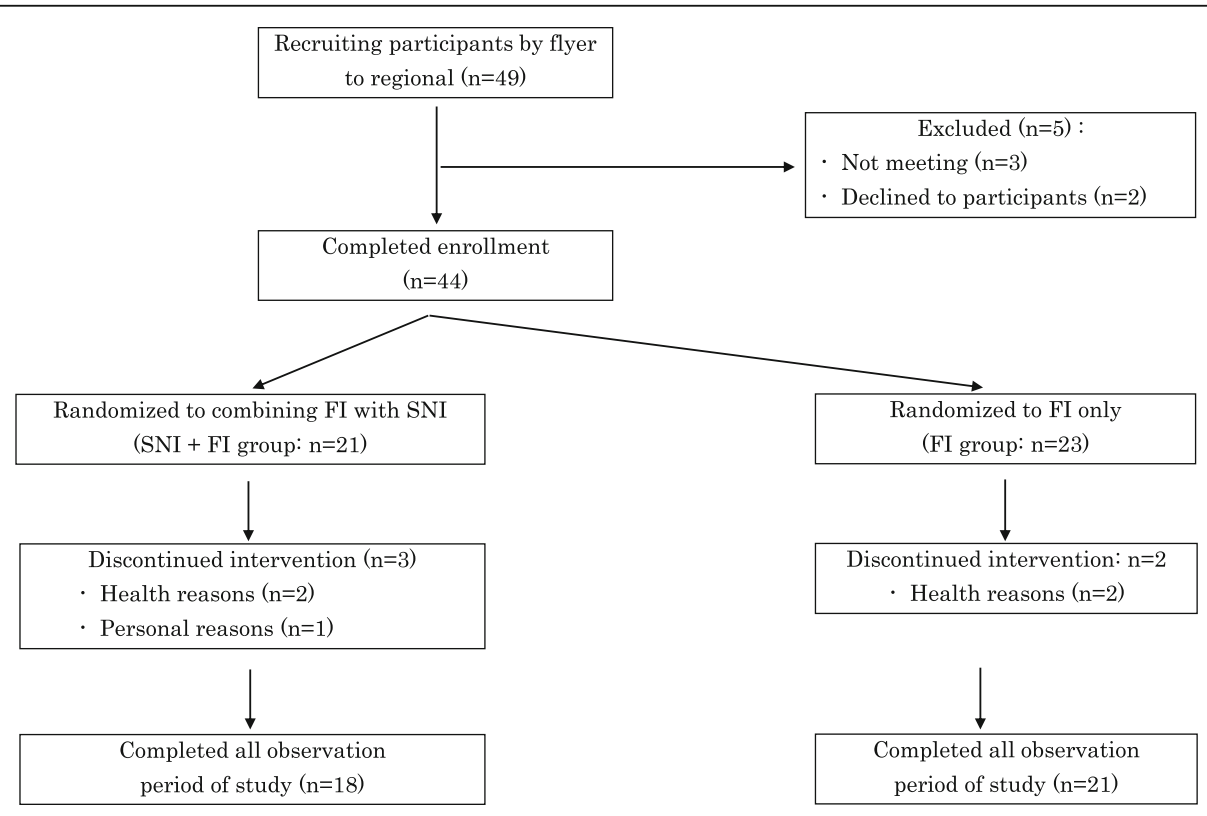

Fig. 1 Flow diagram of the two groups' progress through the phases the randomized trial 
adult body fat $\%=(1.20 \times \mathrm{BMI})+(0.23 \times$ age $)-(10.8 \times$ sex)-5.4 [28].

\section{Physical activity}

Before starting the study, a pedometer (EX-500, YAMASA TOKEI KEIKI CO., LTD, Tokyo, Japan) was given to each participant to measure the number of steps per day. Each participant also received a diary to record their daily step count (pedometer). The SNI + FI group kept record in the diary when three people walked together. For the evaluation of the number of steps, the average daily step count for 1 month was calculated based on the number of steps written in the diary. To manage the accuracy of the total number of steps, researchers collated the pedometer's weekly data when participants submitted their diaries.

\section{Social capital}

The measurement of social capital used trust, network, and social participation by referring to Yang's report [29]. Trust and network of social capital was surveyed using a questionnaire created by the Japanese Cabinet Office. The trust was assessed by a single item: "Generally speaking, would you think that most people can be trusted?" The responses were selected using a Likert scale [30]. The network used two questions. The first question was regarding "Relationship with neighbors." This question included a four-point scale (none; would greet; would talk while standing; would consult with life concerns). The second question concerned the "Number of neighbors with whom one has a relationship." This was also a four-point scale with the following possible answers: zero, four or fewer people, five to nineteen people, and twenty people or more.

From a previous study by the Japan Science and Technology Agency Index of Competence (JST-IC), the social participation was assessed using four items [31, 32]. The four items were as follows: (1) Participate in regional events; (2) Participate in a neighborhood association; (3) Assume a managerial position or role such as the leader in a residents' association; and (4) Engage in charity. These items were assessed using $\mathrm{Yes}=1 / \mathrm{No}=2$, and the points were summed. All these measurements were of undefined time frame.

For social capital, individual indexes were calculated by standardizing (calculated so that the mean was " 0 " and the standard deviation and variance were "1") each item. The standardization formula was $Y=\frac{X-\mu}{\sigma}$. In this formula, $X$ represented the data, $\mu$ the mean of $X$, and $\sigma$ the standard deviation.

\section{Statistical analysis}

Data were analyzed using SPSS Statistics 20.0 (IBM Corporation, Tokyo, Japan). All descriptive and statistical data are shown as the mean $\pm S D$. An unpaired t-test was used to compare the differences in age, body height, body weight, BMI, and percentage of body fat between the FI group and SNI + FI group before the intervention. Two-way repeated-measures ANOVA was conducted to compare the effects of the intervention and the sixmonth postintervention physical activity and social capital between groups. Post hoc analyses were conducted using simple main effects. The partial eta squared $(\eta 2$ p) was used to assess the effects size from the ANOVA analyses. The significance level was set at $p<0.05$.

\section{Results}

Before the intervention, there were no significant differences in age, body height, body weight, BMI, or percentage of body fat between the FI group and the SNI + FI group (Table 1). A two-way ANOVA revealed that in terms of physical activity, there was a statistically significant interaction between group and time $(\mathrm{F}(1,37)=$ $6.24, p=0.017$, Fig. 2). The physical activity of the SNI + FI group increased significantly between the preintervention and the six-month postintervention periods ( $\mathrm{F}(2$, 36) $=5.41, p=0.006$, Fig. 2). However, the FI group

Table 1 Comparison of Clinical Characteristics between SNI + Fl group and FI group

\begin{tabular}{|c|c|c|c|c|}
\hline & $\begin{array}{l}\text { All } \\
n=39\end{array}$ & $\begin{array}{l}\text { SNI + FI group } \\
n=18\end{array}$ & $\begin{array}{l}\text { FI group } \\
n=21\end{array}$ & $P$ \\
\hline Age (years) & $71.9 \pm 5.7$ & $73.5 \pm 6.3$ & $70.6 \pm 4.9$ & 0.11 \\
\hline Body height $(\mathrm{cm})$ & $155.3 \pm 6.8$ & $153.7 \pm 8.0$ & $156.6 \pm 5.5$ & 0.19 \\
\hline Body weight (kg) & $53.7 \pm 8.7$ & $51.3 \pm 7.6$ & $55.8 \pm 9.2$ & 0.11 \\
\hline Body mass index (kg/m2) & $22.2 \pm 2.8$ & $21.8 \pm 3.2$ & $22.6 \pm 2.4$ & 0.36 \\
\hline Percentage of body fat(\%) & $37.3 \pm 4.0$ & $37.1 \pm 5.3$ & $37.5 \pm 2.7$ & 0.77 \\
\hline Trust & $0.0 \pm 1.0$ & $-0.2 \pm 1.1$ & $0.2 \pm 1.0$ & 0.18 \\
\hline Network & $0.0 \pm 1.9$ & $-0.5 \pm 1.6$ & $0.4 \pm 2.0$ & 0.12 \\
\hline Social participation & $-0.2 \pm 0.9$ & $0.0 \pm 1.0$ & $-0.4 \pm 0.8$ & 0.12 \\
\hline
\end{tabular}

Values are expressed as the mean $\pm S D$ 


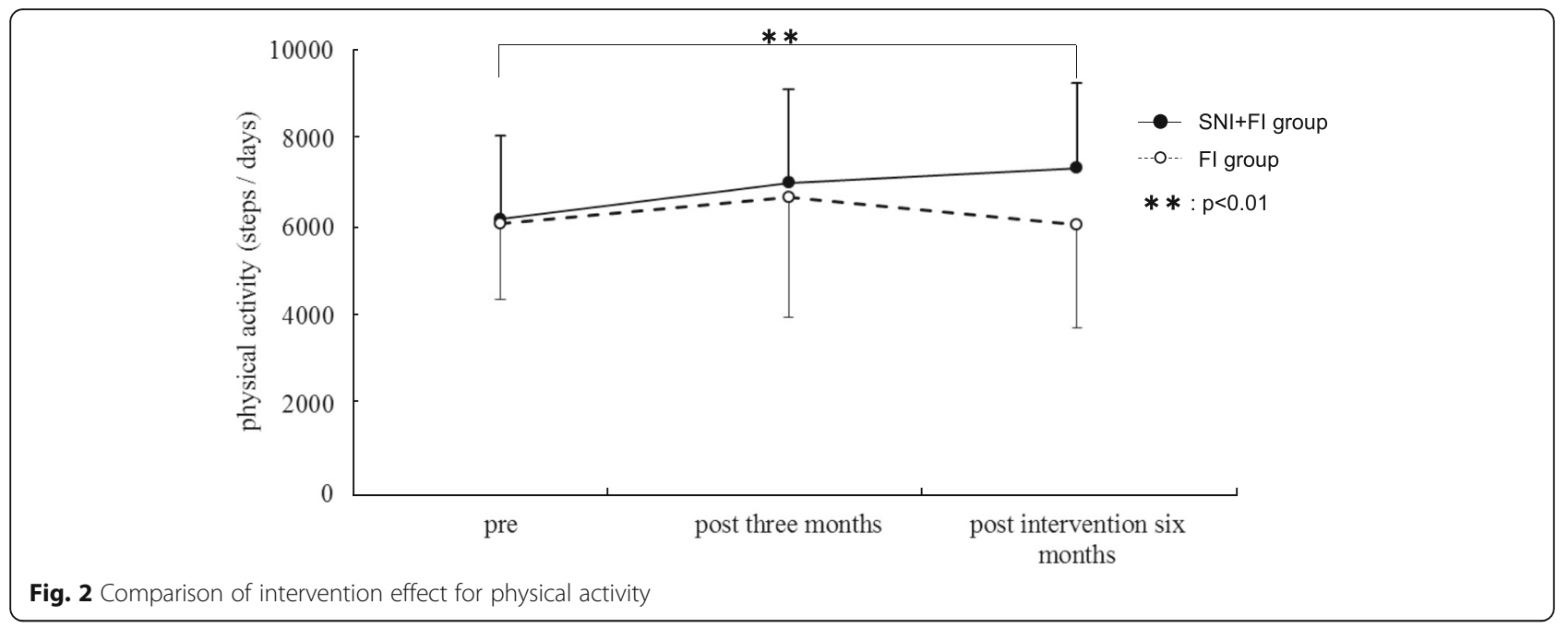

showed no statistically significant improvement in physical activity during the observation period (Fig. 2). In terms of social capital, a two-way ANOVA revealed that, in trust, networking and the JST-IC, there was no significant interaction (trust, $p=0.08$; network, $p=0.18$; JSTIC, $p=0.84$, Table 2). The social capital analysis results were the same regardless of standardization (not shown).

\section{Discussion}

The results of this study suggest that the combined effects of social network incentives and financial incentives continued after the intervention and increased physical activity in older women, but those receiving only financial incentives were not as effective in this study.

Aharony et al. [21] focused on social network incentives leveraging the power of peer pressure by using peer rewards. In their experiments, the process by which the target participants' good behavior rewards the "buddy" enhanced the physical activity of both the target and the "buddy." Furthermore, the study found that increased physical activity continues after the intervention has ended when financial incentives are combined with social network incentives. Therefore, in our study, although there was no effect during the intervention period, we expected the effect on the increase in physical activity to continue after the intervention. In addition, the results of our study are consistent with those of Aharony et al. However, a key distinction of our study is that it is the first to investigate whether social network incentives have beneficial effects on physical activity among older persons after an intervention using a randomized study.

In a previous study about the effects of financial incentives alone, it was found that even when tangible rewards were offered, they decreased intrinsic motivation for activity [18]. Additionally, the rewards are likely to be accompanied by surveillance, evaluation, and competition, which have also been found to undermine intrinsic motivation [33]. For these reasons, our study concluded that financial incentives alone did not increase physical activity during the intervention period. Conversely, if the rewards were higher, physical activity might have increased. High financial incentives, with total possible rewards exceeding $\$ 100$, have been found to create change in behavior [34, 35]. However, once the incentives are no longer apparent, lasting effects have been

Table 2 Comparison of intervention effects for physical activity and social capital variable

\begin{tabular}{|c|c|c|c|c|c|c|c|c|}
\hline & e & $\mathrm{SNI}+\mathrm{FI}$ group & & & FI grou $p$ & & & Interaction \\
\hline & $\mathrm{pr}$ & $\begin{array}{l}\text { post } \\
3 \text { months }\end{array}$ & $\begin{array}{l}\text { post } \\
\text { intervention } \\
6 \text { months }\end{array}$ & pre & $\begin{array}{l}\text { post } \\
3 \text { months }\end{array}$ & $\begin{array}{l}\text { post } \\
\text { interventi on } \\
6 \text { months }\end{array}$ & $\begin{array}{l}\text { main } \\
\text { effect of time }\end{array}$ & \\
\hline $\begin{array}{l}\text { Physical } \\
\text { activity } \\
\text { (steps/day) }\end{array}$ & $6194.7 \pm 1879.6$ & $7014.6 \pm 2098.6$ & $7353.5 \pm 1908.2^{* *}$ & $6102.9 \pm 1728.6$ & $6696.0 \pm 2714.6$ & $6073.4 \pm 2335.5$ & 0.02 & 0.02 \\
\hline Trust & $0.2 \pm 1.1$ & $0.2 \pm 0.9$ & $0.2 \pm 0.8$ & $0.2 \pm 1.0$ & $-0.1 \pm 1.1$ & $-0.1 \pm 1.2$ & 0.107 & 0.08 \\
\hline Network & $0.5 \pm 1.6$ & $-0.7 \pm 1.6$ & $-0.3 \pm 1.5$ & $0.4 \pm 2.0$ & $0.1 \pm 1.8$ & $0.0 \pm 1.6$ & 0.820 & 0.175 \\
\hline $\begin{array}{l}\text { Social } \\
\text { participation }\end{array}$ & $0.0 \pm 1.0$ & $0.3 \pm 1.2$ & $0.3 \pm 1.0$ & $0.4 \pm 0.8$ & $-0.3 \pm 0.8$ & $-0.2 \pm 0.9$ & -0.846 & 0.839 \\
\hline
\end{tabular}

Values are expressed as the mean $\pm \mathrm{SD}^{* *}$

simple main effect compared to pre intervention, $p<0.01$ 
observed only in a few cases. Therefore, it is interesting that by using social network incentives, even low financial incentives have beneficial effects on physical activity in older persons, even after an intervention. Additionally, in older persons, maintaining increased physical activity will not only prevent cardiovascular disease and improve QOL $[1-4,6,7]$ but also prevent cognitive function and depression [8-11], which may prevent receipt of care.

In our research, we examined whether physical activity interventions increased individual-level social capital, however, we were unable to prove our hypothesis. Several previous studies have shown that increasing individual-level social capital is not easy. In their study on social capital intervention, Moore et al. summarized that it is important to increase network diversity [36]. In addition, Ottesen et al. [37] conducted a focus group interview on team sports to enhance social capital. Furthermore, we used the I-, weand they-stories as a technique for building social capital. Based on these previous studies, we considered that further intervention is necessary in this study. For example, we may have enhanced social capital by creating opportunities for participants in this study to interact with large groups and approach individuals.

Putnam and Feldstein's study [38] showed that smaller groups with face-to-face communication promote empathy about the factors that create social capital among the participants. In our study, we formed groups of three people to create the power of peer pressure. We believe that groups of three people are the minimum size necessary to maximize social network incentives and that even numbers have the risk of causing division. Additionally, previous studies have shown an association between individual-level social capital, and self-rated physical and mental health [39-41]. Therefore, increasing the number of people walking with buddies in the region may contribute to the development of local social capital and health.

There were a few limitations to this study. First, the sample was small, with females only, and we limited the study to Japan's regions only. Additionally, because our sample was healthy, the results may not be generalizable to less healthy people, men, and other racial or ethnic groups. Future studies should involve a large number of participants and men. Second, although a randomized design was employed, the study enrolled only those persons who voluntarily responded to an advertisement and agreed to participate in the program. Third, the researchers only collated the pedometer and diary data for 1 week, and not the data beyond that timeframe. Moreover, because physical activity was measured using a pedometer, we could not quantify other forms of physical activity, such as cycling or swimming. Finally, it is unclear whether different incentive designs would yield greater effectiveness at a lower cost.

\section{Conclusion}

Our results suggest that social network incentives combined with financial incentives are more effective for promoting physical activity among older women than financial incentives alone and that these effects can continue postintervention. We therefore recommend a sustainable walking program that can lead to better health for older persons. In the meantime, further studies should be conducted on the effect of physical activity on social capital.

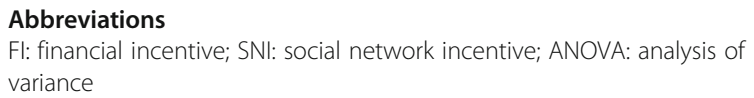

\section{Acknowledgments}

The authors wish to thank all the participants in this research. We would like to acknowledge the staff of the Kumamoto Institute of Total Fitness for their support.

\begin{abstract}
Authors' contributions
RY was a major contributor in writing and revising the manuscript, who conducted the analysis, and interpreted the results. SS made substantial contributions to the study design, writing and revising of the manuscript, and assisting the interpretation of the results. RA made substantial contributions to the conception and drafting the work. As a health promotion expert, ST conducted the statistical analysis and provided professional interpretation. TD, TY, SO, and EH made substantial contributions to the conception and design of the study. All authors read and approved the final manuscript.
\end{abstract}

\section{Funding}

This work was supported by MEXT KAKENHI Grant Number NO17K01810. The details are the purchase of pedometers and gift cards, and proofreading of the research papers

Availability of data and materials

The datasets used and/or analyzed during the current study are available from the corresponding author on request.

Ethics approval and consent to participate

Ethical approval for the study was granted by the ethics committee of Osaka Sangyo University (2017-JINRIN-016). Written informed consent was obtained from each participant before data collection.

Consent for publication

Not applicable.

Competing interests

The authors declare that they have no competing interests.

\section{Author details}

${ }^{1}$ Kumamoto Institute of Total Fitness, 6-8-1 Yamamuro, Kita-ku, Kumamoto 860-8518, Japan. ${ }^{2}$ Teikyo Heisei University, 2-51-4 Higashiikebukuro, Toyosima-ku, Tokyo 170-8445, Japan. ${ }^{3}$ Kumamoto Kinoh Hospital, 6-8-1 Yamamuro, Kita-ku, Kumamoto 860-8518, Japan. ${ }^{4}$ Dynamic Sports Medicine Institute, 1-10-28 Nishishinsaibashi, Chuo-ku, Osaka 542-0086, Japan. ${ }^{5}$ Kumamoto University, 2-39-1 Kurokami, Chuo-ku, Kumamoto 860-8555, Japan. ${ }^{6}$ Osaka Sangyo University, 3-1-1 Nakagaito, Dito-city, Osaka 574-8530, Japan. 
Received: 22 September 2019 Accepted: 5 January 2021

Published online: 21 January 2021

\section{References}

1. Rockhill B, Willett WC, Manson JE, Leitzmann MF, Stampfer MJ, Hunter DJ, et al. Physical activity and mortality: a prospective study among women. Am J Public Health. 2001;91(4):578-83.

2. Pate RR, Pratt M, Blair SN, Haskell WL, Macera CA, Bouchard C, et al. Physical activity and public health : A recommendation from the Centers for Disease Control and Prevention and the American College of Sports Medicine. JAMA. 1995:273:402-7.

3. Li J, Siegrist J. Physical activity and risk of cardiovascular disease-a metaanalysis of prospective cohort studies. Int J Environ Res Public Health. 2012; 9(2):391-407.

4. Samitz G, Egger M, Zwahlen M. Domains of physical activity and all-cause mortality: systematic review and dose-response meta-analysis of cohort studies. Int J Epidemiol. 2011;40(5):1382-400.

5. Wong CH, Wong SF, Pang WS, Azizah MY, Dass MJ. Habitual walking and its correlation to better physical function: implications for prevention of physical disability in older persons. J Gerontol A Biol Sci. 2003;58(6):555-60.

6. Balboa-Castillo T, Leon-Munoz LM, Graciani A, Rodriguez-Artalejo F, GuallarCastillon P. Longitudinal association of physical activity and sedentary behavior during leisure time with health-related quality of life in community-dwelling older adults. Health Qual Life Outcomes. 2011:9:47.

7. Bize R, Jhonson JA, Plotnikoff RC. Physical activity level and health-related quality of life in the general adult population: a systematic review. Prev Med. 2007:45(6):401-15.

8. Barnes DE, Whitmer RA, Yaffe K. Physical activity and dementia: the need for prevention trials. Exerc Sport Sci Rev. 2007;35(1):24-9.

9. Lautenschlager NT, Cox KL, Flicker L, Foster JK, van Bockxmeer FM, Xiao J, et al. Effect of physical activity on cognitive function in older adults at risk for Alzheimer disease: a randomized trial. JAMA. 2008;300(9):1027-37.

10. Dunn AL, Trivedi MH, Kampert JB, Clark CG, Chambliss HO. Exercise treatment for depression: efficacy and does response. Am J Prev Med. 2005; 28(1):1-8.

11. Mather AS, Rodriguez C, Guthrie MF, McHarg AM, Reid IC, McMurdo ME. Effects of exercise on depressive symptoms in older adults with poorly responsive depressive disorder: randomized controlled trial. Br J Psychiatry. 2002;180:411-5.

12. Lee IM. Physical activity and cancer prevention--date from epiodemiologic studies. Med Sci Sports Exerc. 2003;35(11):1823-7.

13. Mc TA. Mechanisms linking physical activity with cancer. Nat Rev Cancer. 2008;8(3):205-11.

14. Ministry of Health, Labour, Welfare. A basic direction for comprehensive implementation of national health promotion. Ministerial Notification No. 430 ?of the Ministry of Health, Labour and Welfare; 2012. P. 1-25.

15. Cook M, Greer E, Murray K, Mcgeown P, McVicker D, Ruddy M. Promoting Physical Activity with Older People. http://www.sportni.net/sportni/wpcontent/uploads /2013/03/PromotingPhysicalActivityOlderPeople.pdf.

16. Finkelstein EA, Brown DS, Brown DR, Buchner DM. A randomized study of financial incentives to increase physical activity among sedentary older adults. Prev Med. 2008;47(2):182-7.

17. Farooqui MA, Tan YT, Bilger M, Frinkelstein EA. Effects of financial incentives on motivating physical activity among older adults: results from a discrete choice experiment. BMC Public Health. 2014;14:141.

18. Deci EL, Koestner R, Ryan RM. A meta-analytic review of experiments examining the effects of extrinsic rewards on intrinsic motivation. Psychol Bull. 1999;125(6):627-68.

19. Carrera M, Royer H, Stehr M, Sydnor J. Can financial incentives help people trying to establish new habits? Experimental evidence with new gym members. J Health Econ. 2018:58:202-14.

20. Mani A, Rahwan I, Pentland A. Including peer pressure to promote cooperation. Sci Rep. 2013;3:1735.

21. Aharony N, Pan W, Ip C, Khayal I, Pentland A. Social fMRI: investigating and shaping social mechanisms in the real world. Pervasive Mobile Computing 2011;7:643-59.

22. Brach JS, FitzGerald S, Newman AB, Kelsey S, Kuller L, VanSwearingen JM, et al. Physical activity and functional status in community-dwelling older women: a 14-year prospective study. Arch Inter Med. 2003;163:2565-71.

23. Aihie-Sayer A. D ennison EM, Syddall HE, Jameson K, Martin HJ, Cooper C. the developmental origins of sarcopenia: using peripheral quantitative computed tomography to assess muscle size in older people. J Gerontol A Biol Sci Med Sci. 2008:63(8):835-40.

24. Berkman LF, Glass T. Social integration, social networks, social support, and health. In: Berkman LF, Kawachi I, editors. Social Epidemiology. New York: Oxford University Press; 2000. p. 137-73.

25. Cohen S, Underwood LG, Gottlieb BH. Social support measurement and intervention: A guide for health and social scientists. New York: Oxford University Press; 1990.

26. Durkheim E. Suicide: A study in sociology. Glencoe: Free Press 1897, 1951.

27. Yamashita R, Sato S, Akase R, Doi T, Tsuzuku S, Yokoi T. Effects of social network incentives and financial incentives on physical activity among elderly women. Med Sci Sports Exerc. 2019;51:203. https://doi.org/10.1249/ 01 mss.0000561114.39038.76

28. Deurenberg P, Weststrate JA, Seiedell JC. Body mass index as a measure of body fatness: age- and sex-specific prediction. Br J Nutr. 1991:65(2):105-14.

29. Yang K. Individual social capital and its measurement in social surveys. Survey Research Methods. 2007;1(1):19-27.

30. Ueshima K, Fujiwara T, Takao S, Suzuki E, Iwase T, Doi H, et al. Does social capital promote physical activity? A population-based study in Japan. PLoS One. 2010;5(8):e12135.

31. Iwasa $H$, Masui $Y$, Inagaki $H$, Yoshida $Y$, Shimada $H$, Otsuka $R$, et al. Assessing competence at a higher level among older adults: development of the Japan Science and Technology Agency index of competence (JST-IC). Aging Clin Exp Res. 2018;30(4):383-93.

32. Iwasa $H$, Masui $Y$, Inagaki $H$, Yoshida $Y$, Shimada $H$, Otsuka R, et al. Development of the Japan Science and Technology Agency index of competence (JST-IC) to assess functional capacity in older adults: conceptual definitions and preliminary items. Gerontol Geriatr Med. 2015;1: 233372145609490; doi: https://doi.org/10.1177/2333721415609490.

33. Deci EL, Ryan RM. Intrinsic motivation and self-determination in human behavior. New York: Plenum Press. 1985. https://doi.org/10.2307/2070638.

34. Charness G, Greezy U. Incentives to exercise. Econometrica. 2009;77(3):90931.

35. Royer $H$, Stehr M, Sydnor J. Incentives, commitments, and habit formation in exercise: evidence from a field experiment with workers at a fortune-500 company. Am Econ J Appl Econ. 2015;7(3):51-84.

36. Moore S, Bockenholt U, Daniel M, Frohlich K, Kestens Y, Richard L. Social capital and core network ties: a validation study of individual-level social capital measures and their association with extra- and intra-neighborhood ties, and self-rated health. Health Place. 2011;17:536-44.

37. Ottesen L, Jeppesen RS, Krustrup R. The development of social capital through football and running: studying an intervention program for inactive women. Scand J Med Sci Sports. 2010;20(1):118-31.

38. Putnam RD, Feldstein L. Better together. Restoring the American community. New York: Simon and Schuster; 2003.

39. Rose R. How much does social capital add to individual health? A survey study of Russians. Soc Sci Med. 2000;51(9):1421-35.

40. Berry HL, Welsh JA. Social capital and health in Australia: an overview from the household, income and labour dynamics in Australia survey. Soc Sci Med. 2010;70(4):588-96.

41. Nieminen T, Martelin T, Koskinen S. Social capital as a determinant of selfrated health and psychological well- being. Int J Public Health. 2010;55(6): 531-42.

\section{Publisher's Note}

Springer Nature remains neutral with regard to jurisdictional claims in published maps and institutional affiliations.

Ready to submit your research? Choose BMC and benefit from:

- fast, convenient online submission

- thorough peer review by experienced researchers in your field

- rapid publication on acceptance

- support for research data, including large and complex data types

- gold Open Access which fosters wider collaboration and increased citations

- maximum visibility for your research: over $100 \mathrm{M}$ website views per year

At $\mathrm{BMC}$, research is always in progress.

Learn more biomedcentral.com/submission 